\title{
Contrast-enhanced MRI of the knee in asymptomatic pediatric controls compared to juvenile idiopathic arthritis patients to validate synovitis scores
}

\author{
Charlotte M Nusman ${ }^{1,2^{*}}$, Robert Hemke ${ }^{1}$, Marc Benninga ${ }^{3}$, Angelika Kindermann ${ }^{3}$, Marion van Rossum ${ }^{4,5}$, \\ Taco Kuijpers ${ }^{2}$, Mario Maas ${ }^{1}$
}

From 21st European Pediatric Rheumatology (PReS) Congress

Belgrade, Serbia. 17-21 September 2014

\section{Introduction}

The primary target of disease in juvenile idiopathic arthritis (JIA) is inflamed synovium, i.e. synovitis, which can be best visualized with magnetic resonance imaging (MRI) upon administration of intravenous (IV) contrast. Adequate differentiation between pathologic from physiologic extent of synovial enhancement has important implications for (dis)continuation of therapy.

\section{Objectives}

To describe the appearance of the healthy knee on MRI after IV contrast and to compare the enhancing synovium in asymptomatic children to JIA patients.

\section{Methods}

An axial fat-saturated T1-weighted MRI sequence of the knee of 25 asymptomatic controls and 25 JIA patients was collected, blinded and randomized. The asymptomatic controls were children who underwent MR enterography with IV contrast for unrelated diseases, had no (history of) joint complaints or signs of joint inflammation and gave permission for an additional sequence of the knee. JIA patients were age/sex-matched and divided in three clinical subgroups: new-active, relapse and inactive. Two readers independently scored synovial hypertrophy $(\mathrm{SH})$ on a scale from 0-2 (none, $2-4 \mathrm{~mm}, \geq 4 \mathrm{~mm}$ ) at six locations, based on the Juvenile Arthritis MRI Scoring system (JAMRIS). Afterwards agreement on incongruent cases was obtained. Differences in SH score and (subgroups) of JIA patients were assessed.

${ }^{1}$ Radiology, Academic Medical Center, Netherlands

Full list of author information is available at the end of the article

\section{Results}

Mean age of all subjects ( $42 \%$ female) was 13.5 years (SD 2.5). Contrast-enhanced thickened synovium was present upon imaging of the knee in $60 \%$ of the controls (total SH score range 1-3) and $76 \%$ of the patients. A significant difference $(\mathrm{p}=0.007)$ in the total $\mathrm{SH}$ score was found between controls and JIA children. SH score could differentiate controls from the clinically active JIA subgroup $(\mathrm{p}=0.002)$ but not from the clinically inactive JIA subgroup $(p=0.303)$. Findings only observed in the asymptomatic group consisted of an diffuse 'contrastoutfading' pattern in $28 \%$ of the controls and 'pseudoenhancement' of the cartilage at the posterior condyles only, that could be mistaken for true synovial inflammation.

\section{Conclusion}

In asymptomatic children only very mild synovial enhancement was detected as well as two as yet undescribed findings representing potential pitfalls in the assessment of disease activity upon MRI of the knee. The existing, very reliable JAMRIS system for assessment of enhancing synovium can differentiate JIA patients from asymptomatic controls but only at group-level. For individual differentiation improved MRI scoring needs to be developed avoiding the measurement of synovial thickness scoring to further establish MRI as more accurate monitoring tool for JIA disease activity.

\section{Disclosure of interest}

None declared. 


\section{Authors' details}

${ }^{1}$ Radiology, Academic Medical Center, Netherlands. ${ }^{2}$ Pediatric Hematology, Immunology, Rheumatology and Infectious Disease, Netherlands. ${ }^{3}$ Pediatric Gastroenterology, Emma Children's Hospital AMC, Netherlands. ${ }^{4}$ Pediatrics, Emma Children's Hospital AMC, Netherlands. ${ }^{5}$ Pediatric Rheumatology, Reade Institute, location Jan van Breemen, Amsterdam, Netherlands.

Published: 17 September 2014

doi:10.1186/1546-0096-12-S1-P14

Cite this article as: Nusman et al:: Contrast-enhanced MRI of the knee in asymptomatic pediatric controls compared to juvenile idiopathic

arthritis patients to validate synovitis scores. Pediatric Rheumatology 2014 12(Suppl 1):P14.

Submit your next manuscript to BioMed Central and take full advantage of:

- Convenient online submission

- Thorough peer review

- No space constraints or color figure charges

- Immediate publication on acceptance

- Inclusion in PubMed, CAS, Scopus and Google Scholar

- Research which is freely available for redistribution

Submit your manuscript at www.biomedcentral.com/submit
C Biomed Central 